\title{
LAS ASOCIACIONES DE BANCO DE TIEMPO: ENTRE LA RECIPROCIDAD Y EL MERCADO
}

\author{
Gonzalo SANZ CASAS \\ Departament de Antropologia Social, Universidad de Barcelona
}

ABSTRACT: The author argues that reciprocity has to be refined if we want to use it as a valid tool of analysis for the interpretations of relationships not mediated by the market or by the Welfare State.

\section{Presentación}

El objetivo de este artículo es el de plantear si la reciprocidad, un concepto que describe aquellas relaciones socioeconómicas que se producen fuera del mercado, es operativo para analizar ciertos tipos de estrategias y comportamientos socioeconómicos, públicos y privados, en las actuales economías regidas por la hegemonía del mercado. Más en concreto, este artículo reflexiona sobre los límites y alcances del concepto de reciprocidad en relación a una asociación de "Banco de Tiempo", entendida como uno de los exponentes más característicos de las organizaciones «solidarias» surgidas como alternativa social y económica al desmantelamiento del Estado del Bienestar.

En los últimos años, el concepto de capital social ha adquirido una importancia clave para explicar el "éxito» de las políticas de desarrollo económico. Lo que nos interesa destacar es que el concepto de capital social, fundamental para explicar por ejemplo la "nueva" cultura empresarial y la organización económica flexible en el modelo de los Distritos Industriales a partir de la experiencia en el norte de Italia, incorpora la idea de la importancia de las relaciones so-

1 Este texto forma parte del Proyecto de Investigación PB98, Programa Sectorial de Promoción General del Conocimiento. 
ciales no económicas, de las redes sociales y, en general, de las relaciones sociales informales en la dinámica de los desarrollos económicos locales.

El valor del concepto de capital social, entendido como individualidad que anuncia nuevas formas identitarias de los miembros de la sociedad, supone el surgimiento de una moralidad en la economía que desde la ciudadanía $-\mathrm{y}$ también desde las instituciones públicas - se expresa en iniciativas asociativas y de red como, por ejemplo, el trueque, los bancos de tiempo, el voluntariado, las prestaciones sociales, etc., que podríamos etiquetar como trabajo cívico. Por otra parte, este tipo de prácticas sociales y económicas inciden en la idea de la incrustación de lo económico en lo social, en la consideración de que los hechos económicos son hechos sociales.

I. El concepto de reciprocidad es un concepto clave del análisis antropológico que describe formas de interracción social que no están guiadas por la lógica del mercado. Uno de los usos más comunes se refiere a aquellos intercambios en los que el cálculo de equivalencias entre bienes o servicios transferidos y los tiempos de cierre de la transacción no quedan definidos de antemano.

Este tipo de relaciones se pueden enmarcar en distintos grados en el concepto de reciprocidad, forman parte de las acciones presentes en las sociedades, tanto en el ámbito privado como público, en las funciones domésticas, educativas, empresariales, políticas, etc.

Además, las políticas actuales de los países desarrollados con dificultades de financiación de los programas sociales, que se enfrentan a transformaciones socioeconómicas importantes (cambios demográficos, paro estructural, nuevas formas de producción, multiculturalismo, etc.) tratran de fomentar relaciones sociales de reciprocidad bajo el nombre de solidaridad.

En 1998, un informe del Club de Roma sugiere la necesidad de ampliar y contabilizar como recursos para la economía ámbitos no regulados por el mercado, como son los del trabajo doméstico, el comunitario, la autoproducción, el voluntariado, la ayuda mutua en los servicios, etc.; es decir, todos los que se sustentan en relaciones de reciprocidad. Este mismo informe señala la pertinencia de articular estas formas de relación no mercantiles a las relaciones instituidas a través del mercado para diseñar las políticas económicas y sociales.

Como es sabido, en la teoría del intercambio recíproco, la entrega de regalos ocupa un lugar importante en la historia de la antropología. Para M.Mauss, el intercambio de regalos era una de las forma de reciprocidadobligatoria que 
expresaba las relaciones sociales, tanto a nivelindividual como de grupo, de los sistemas sociales primitivos. Así, en el análisis_socioeconómico del intercambio de regalos propuesto por M.Mauss, los bienes transferidos tenían un valor social o moral, pero no un valor económico en sí. El intercambio de regalos favorecía parte de un sistema de prestaciones totales en que los individuos de la sociedad tenían que dar, recibir y devolver bajo la amenaza de la sanción.

Una de las objecciones a la teoría de la reciprocidad, a la definición de reciprocidad, es de carácter contextual. De hecho, la definición de M.Mauss de la reciprocidad en base a tres obligaciones - dar, recibir, devolver- es restrictiva en el sentido de que su validez se limita a dos ámbitos de la vida social, el de la amistad y el de la hospitalidad, siempre y cuando se dé en estos ámbitos el valor moral de la generosidad. De ahí que sea pertinente la revisión de la teoría de la reciprocidad al señalar que precisamente son los ámbitos los que pueden dotar de sentido a una teoría de la reciprocidad ${ }^{2}$.

De acuerdo con esta línea argumental, la teoría del intercambio económico de K.Polanyi adquiere singular relevancia en la reflexión del concepto de reciprocidad. La propuesta de K.Polanyi de la incrustación de lo económico en lo social, situa el análisis del intercambio recíproco en el dominio de los ámbitos, de los contextos sociales y culturales; de tal modo que el análisis de las transacciones económicas exige el marco referencial de las relaciones sociales vigentes, hegemónicas o no, en la sociedad.

II. Antes nos hemos referido al interés institucional por los ámbitos de actividad económica no regulados por el mercado y la conveniencia de articular estas formas de relación no mercantilizadas a las relacions instituidas mediante el mercado, con el objetivo de implementar políticas económicas y sociales. En este sentido, un número importante de antropólogos, sociólogos, economistas y psicólogos han prestado atención a todas aquellas formas de relaciones informales que pueden contribuir a consolidar el tejido social y que están presentes en ámbitos altamente institucionalizados como el económico y el político.

Desde que K.Hart, a principios de los años setenta del siglo XX, acuñara el término sector informal para identificar aquellas actividades económicas que se producen al margen de la economía formal, los debates sobre la naturaleza

2 Seminario del grupo de investigación "La Reciprocidad como recurso Humano", comunicación de I. TERRADAS "¿Reciprocidad para qué?". 
de la llamada economía sumergida se han sucedido con relativo poco éxito. En el marco de la reflexión sobre las relaciones socioeconómicas informales, nos parece particularmente sugerente la propuesta de J. Gershuny. Este autor centra la atención en la economía informal, diferenciándola de la economía subterránea, y señala que la economía informal es una economía que se basa en la producción no monetaria de servicios en el hogar, que sustituye a la producción de servicios en la economía formal. Los flujos que tienen lugar en el interior de las familias no se basan, en general, en ningún intercambio específico y explícito de cantidades definidas de mercancías. Estos intercambios dentro de las familias son generalizados e implícitos, no están cuantificados y con frecuencia son a largo plazo.

Para J.Gershuny, asociado al sistema de producción doméstico está el sistema de producción comunitario. Se trata de organizaciones voluntarias o religiosas, transportes cooperativos, cooperativas para la reforma de viviendas, etc. En los extremos de la diversidad asociativa del sistema comunitario, encontramos organizaciones muy próximas al sistema de producción formal (por ejemplo, los grupos de cuidadores de niños o los que se alternan en el uso de los respectivos automóviles), actuan sobre la base de un intercambio casi monetario mediante créditos o fichas; y otras, más generalizadas, que disponen de un sistema de intercambio específico, siendo la razón principal de su participación en las actividades de la red la remuneración intangible, simbólica y no cuantificada de las mismas: el dinero real no se utiliza como indicador de intercambios de valores.

Desde la la crisis económica de 1975, el crecimiento de la economía doméstica y del sector comunitario ha estado promovido por el incremento de los costes de los servicios comprados en el exterior, en relación con la tendencia decreciente del coste de los bienes domésticos del capital. Así, hemos asistido a la exportación de puestos de trabajo de la economía formal a la economía informal; y, desde la racionalidad económica, los individuos han optado por la provisión informal de los servicios. El crecimiento de los sectores de producción doméstico y comunitario implica una disminución de la demanda que se dirige al sector formal productor de servicios, con bajas tasas de aumento de la producción, lo que se traduce en un incremento del desempleo.

En el marco actual de las políticas económicas de signo neoliberal, el Estado en los países desarrollados parece decidido a no suprimir la economía informal, y sí por la promoción activa de los servicios de base comunitaria en camps 
estratégicos de la política social como son, entre otros, el cuidado de los niños, la atención a los ancianos y a los enfermos crónicos. Todo parece indicar que el reconocimiento del capital social y su articulación a las actividades intitucionalizadas en la economía y la polírica, es fundamental para la reproducción del capitalismo en su actual fase de acumulación de capital.

El sistema de producción doméstico y el sistema de producción comunitario son estrategias económicas individuales y de grupo, orientadas al aprovisionamiento de bienes y servicios fuera del mercado. La naturaleza de estas actividades productivas - trabajo, intercambio y consumo- se caracteriza por el dominio de relaciones sociales informales basadas en ámbitos sociales y culturales como la familia, el parentesco, la amistad, la vecindad, el comunalismo, el género, la condición étnica, el corporativismo. etc.

En estos contextos, donde generalmente el trabajo no se paga con dinero y los intercambios son generalizados, el concepto de reciprocidad debe ser revisado. Algunos planteamientos del concepto de capital social utilizan de modo indiscriminado el término reciprocidad para referirse a las relaciones sociales que caracterizan estos ámbitos. Por el contrario, pensamos que el concepto clásico maussiano de reciprocidad pierde validez analítica cuando se aplica en ámbitos distintos a los que aplicó M.Mauss; porque: ¿es la misma reciprocidad la que encontramos en los ámbitos de la amistad y la hospitalidad, que los que se dan en el patronazgo, el ritual, la fiesta, etc.?

III. Una de las organizaciones de intercambio no monetario, generalizado y de ayuda mutua más conocidas, por su difusión y publicitación internacionales en los últimos años, son los LETS (Local Exchange and Trading Systems), siglas que traducidas corresponden a Sistemas de Intercambio y Comercio Local.

En su origen, se trató de un "banco de tiempo»que surgió, en 1983, en Vancouver (Canadá) como respuesta a la crisis de la economía local. Pocos años más tarde, esta iniciativa se extendió a Gran Bretaña en el contexto de la política económica neoliberal de $\mathrm{M}$. Thathcher y adoptó el nombre de LETS. Las asociaciones de los LETS han adquirido dimensiones significativas en los últimos veinte años, de acuerdo con algunos datos y cifras: en Gran Bretaña, en 1999 estaban registrados unos siete mil LETS y se calcula que volumen de los intercambios era equivalente a unos 1.400 millones de pesetas anuales. En Canadá y Estados Unidos el número de LETS es de quince en cada unos de estos países; unos ochenta se han constituído en Nueva Zelanda, unos doscientos en Austra- 
lia, y un número indefinido en Alemania, Bélgica, Austria, Francia y Suiza, mientras que en Italia el número de LETS supera el centenar en la actualidad ${ }^{3}$.

Sin duda, es importante no ignorar los contextos socioeconómicos y políticos para explicar el surgimiento de estas asociaciones como son las crisis económicas, el desempleo, los procesos inflacionarios de la economía, la pérdida de poder adquisitivo de las poblaciones, la crisis de las políticas sociales en los Estados europeos,etc.; es decir, en la mayoría de casos problemas económicos y sociales ligadas al desmantelamiento del Estado del Bienestar. En estas situaciones, los LETS ofrecen un amplio abanico de opciones sociales y económicas de acuerdo con la diversidad de objetivos que presentan y que incluyen desde la reinserción social y económica de grupos sociales precarizados ( parados, mujeres, extoxicómanos, etc.), hasta la difusión de los valores del trueque y la creación de vínculos de ayuda mutua entre los miembros de la red, pasando por la propuesta de una economía alternativa dispuesta a desterrar los conceptos de deuda, pago y acreedor característicos de la economía de mercado ${ }^{4}$.

Un banco solidario de bienes y servicios es una fórmula de intercambio basado en el valores distintos al de las monedas nacionales en circulación en los mercados monetarios nacionales e internacionales. El criterio de medición de un intercambio de bienes o servicios puede ser en horas, o cualquier otro tiempo de medición fijado por una asociación como, por ejemplo, fondones, nodines, iris,... En realidad, el funcionamiento de un banco solidario presenta notables parecidos al de una entidad bancaria, sólo que en los bancos solidarios los activos, los depósitos, son las horas y no el dinero. En el caso de los bancos de tiempos, se intercambia una parte del tiempo personal y profesional de los miembros de la asociación. Este intercambio no es directo, es decir, bilateral entre quien ha prestado unas horas y su beneficiario, sino que los intercambios son generalizados, las demandas y las ofertas se entrecruzan dentro del grupo: "Cada vez que un socio requiere un servicio, la deuda no la contrae con quien se lo presta, sino con todos los socios de la agrupación" 5 .

El centro administrador de la asociación lleva una «contabilidad» de los intercambios entre los socios, envía regularmente "extractos de los movimientos" y apremios a los que están en «números rojos».

3 R. DOMENECH: «El banco del tiempo, una fórmula bancaria para intercambiar horas», en NovaGestió, verano-otońo 2000.

4 Cooperativa Tercer Sector, Vallecas (Madrid). Club de Trueque, Zarautz (Guipúzcoa). Grupo Experimental de Trueque Alternativo (GETA), Segovia.

5 B. AGUIRRE: «Alérgicos al dinero», suplemento El Pats, 13/12/1998:138. 
Una de las experiencias más relevantes de moneda alternativa es La Red Global de Trueque, localizada en Argentina e impulsada a partir de 1995 en el marco del Programa de Autosuficiencia Regional. Entre los objetivos de este programa estaba el de la creación de un tipo de moneda y un sistema de crédito capaces de resolver los problemas de la exclusión social derivados del aumento de la deuda externa, la convertibilidad monetaria, las privatizaciones y los efectos de la globalización económica. Se trataba de generar una red privada de usuarios organizados en clubes de trueque en la que los productos y servicios se cuantificaban en una unidad de medición llamada crédito. Así, se pretendía formar un mercado protegido de bienes y servicios basado en una organización horizontal y una moneda social cuya liquidez se adecuaba al sistema de intercambios de bienes y servicos entre los miembros de la red constituida por los clubes de trueque. El sistema de créditos era la moneda social que se genera mediante un préstamo sin interés, que se otorga periódicamente y de manera equitativa a los usuarios registrados. Las características básicas de la moneda social se resumen en los aspectos siguientes:

1. Los créditos portencian los lazos sociales de la comunidad que intercambian bienes y servicios, basándose en la confianza, orientación y códigos de conducta ética.

2. La red es de trueque, por lo tanto están fuera de lugar las prácticas de carácter finanaciero como el cobro de intereses, cambio de créditos por dinero, retención de porcentajes por ingreso o egreso de productos, comisiones, etc.

3. Aunque haya coincidencias con patrones externos en el cálculo de equivalencias en los intercambios, el paralelismo nominal no implica convertibilidad alguna respecto a algún tipo de dinero o valor.

4. Los vales son una expresión numérica para ordenar y cuantificar intercambios no lucrativos, no teniendo un valor en sí mismo, salvo el de facilitar las relaciones de solidaridad en la producción y la distribución de bienes y servicios.

5. Los créditos son creados para ser trandferidos en forma equitativa mediante préstamos solidarios a los miembros acreditados.

6. El uso de los créditos está restringido al interior de la Red Global de Trueque.

7. El ususario que recibe un préstamo de vales, se compromete (por escrito) como mínimo, a entregar productos $y /$ servicios equivalentes al préstamo recibido. 
8. En caso de que el emisor requiriera la devolución del préstamo, lo hará sin exigir el pago decomisión, intereses ni punitorios.

9. Si el ususario se retirara de la red, debe devolver al emisor exactamente la cantidad de créditos recibidos en préstamo. Además, resigna el derecho a cualquier reclamo por los créditos que tuviera en su poder y superaran el monto otrogado. Deberá seguir haciendo intercambiuos hasta agotarlos.

10. Con este simple mecanismo se atiende a dos cuestiones esenciales: el respaldo y la acumulación. No se necesita un respaldo atesorado dado que cada integrante no es dueño de un valor, ni de un crédito sobre un mercado, sino usuario de un servicio que termina si llegara a retirarse.

11. El crédito es un vale, no por un objeto oservicio en particular, sino por una entidad abstracta llamada "crédito".

Por último, este conjunto de normas reguladoras de los intercambios de bienes y servicos en la Red Global de Trueque es la expresión de una filosofía social que se expresa en el comentario siguiente: "Acumular moneda pone en desventaja a aquel que no latiene y que en cambio solo posee trabajo potencial o productos acopiados...La moneda para que no domine nuestras vidas debe oxidarse con el correr del tiempo. Debe circular para que esté al servicio de la sociedad y no a la inversa. No debe ser atesorada y por ende inmovilizada ya que deja de servir y eseo genera iliquidez, especulación, interés e inflación y desocupación" 6 .

Antes nos hemos referido al interés de las instituciones públicas por el capital social en relación a las políticas de desarrollo económico, por la conveniencia de ampliar y contabilizar como recursos para la economía ámbitos no regulados por el mercado y, en general, por el conjunto de actividades de producción, intercambio y consumo no monetarizadas. En este sentido, los LETS no han quedado al margen: si en Argentina La Red Global de Trueque contó con el impulso del Programa de Autosuficiencia Regional, en otros paises los sistemas de trueque han sido objeto de intervención fiscal por parte de los gobiernos. Así, por ejemplo, en G.Bretaña se establece que si el objeto de trueque no coincide con la propia actividad profesional, no hay obligatoriedad de declaración fiscal; o en Australia, los trabajadores parados podrán intercambiar

${ }^{6}$ http:/www.geocities.com/RainForest/Canopy/5413/index.html. 
en la red de trueque hasta un máximo de veinte horas semanales sin necesidad de declaración fiscal ni de pérdida del subsidio de paro ${ }^{7}$.

La intervención de las instituciones públicas en la promoción y consolidación de las asociaciones de trueque, bancos de tiempo y de ayuda mutua entre ciudadanos nos parece importante en relación a lo expresado con anterioridad. En el caso que presentamos y que es objeto de investigación en la actualidad, una asociación de banco de tiempo que se fundó hace unos tres años en Barcelona, contó desde sus orígenes con el soporte institucional del municipio. El ayuntamiento de Barcelona presentó con la ONG «Salud y Familia», un proyecto al IV Programa de la Comisión Europea. El proyecto fue aprobado y obtuvo una subvención económica que posibilitó la creación de un banco de tiempo vinculado a un Centro de Cultura Popular en un barrio de la ciudad.

En el folleto de presentación de esta asociación se afirma que «el Banc de Temps vol promoure intercanvis per a tasques d'atenció a les persones, siguin criatures, gent grant o gent malalta, i també vol donar oportunitats perquè la gent es conegui i confii en els altres per tal de resoldre necessitats de la vida diària» 8 .

El ayuntamiento de Barcelona colabora en el mantenimiento del local, del teléfono, en reponer el material de oficina y participa en las reuniones que periódicamente se celebran cada dos meses para que los socios se conozcan entre sí 9 .

Esta asociación entrega a la persona que lo solicita y aspira a ser miembro de ésta un reglamento y un talonario con un número de socio, donde apuntará las horas que ha ofrecido. La persona que recibe el servicio firma el talón y la donante envía la matriz a la asociación. Los socios no pagan ninguna cuota, sólo se comprometen a intercambiar tiempo por tiempo.

En la actualidad, esta asociación cuenta con unos 98 socios, en su mayoría pertenecientes al barrio, tienen edades comprendidas entre los 20 y los 75 años, si bien la franja dominante oscila entre los 30 y los 55 años. El $75 \%$ de los socios son mujeres y el $25 \%$ hombres. Los servicios que ofrece esta asocia-

7 R. DOMĖNECH: «El banco de tiempo, una fórmula bancaria para intercambiar horas", NovaGestio, verano-otoño 2000:25.

8 Centre Cívic Guinardo: «El banc de temps. Temps x temps».

9 C. GaSUlL: «El barrio del Guinardó, pionero en crear un banco de tiempo», NovaGestió, verano-otoño 2000:26. 
ción se agrupan en trece epigrafes generales, son los siguientes: Atención a las personas. Cuidado del cuerpo y salud. Estética. Ocio. Tareas domésticas. Música. Idiomas. Informática. Tareas administrativas. Animales de compañía. Bricolaje. Asesoramiento, orientación. Varios.

En este banco puede participar cualquier persona, hombre o mujer, sea del barrio o no. El valor para realizar los intercambios es el tiempo. El tiempo se mide y registra a través de los cheques que la asociación entrega a cada uno de los socios. La persona que es requerida para la realización de un servicio debe comunicar a la gestión de la asociación el número de horas utilizadas junto a los datos del solicitante del servicio.

La gestión del centro registra los intercambios de tiempo entre los socios con el objetivo de establecer un balance de los intercambios a partir del valor tiempo. Sin embargo, la elaboración de este balance de los intercambios de servicios realizados por y entre los socios está dificultado porque, según las personas consultadas, algunos socios cuando realizan los servicios no utilizan los cheques. Así lo expresan algunos socios de la red:«me dijo que no era necesario". "es algo entre nosostros". "no tiene importancia".

Por otra parte, siempre según los informantes, algunos socios son personas muy receptivas ya que muestran mucho interés cuando sus servicios son requeridos, pero en cambio estos mismos socios se resisten a demandar servicios.

Desde nuestro punto de vista, el uso de las metáforas como las de «banco», "talonario", "números rojos", "haber y debe", etc. remite a una dimensión contractual en los intercambios, aunque éstos no tengan valor monetario y sí valor de tiempo. En realidad, cuándo los gestores de la asociación se preocupan por el balance de los intercambios de tiempo, están midiendo, regulando, contabilizando, etc.; es decir, actúan verdaderamente como una entidad bancaria de carácter mercantil. En nuestra opinión, probablemente es una de las razones que explican el por qué los socios se resisten a entregar los talones correspondientes a las prestaciones realizadas.

Si es así, tal vez debemos pensar que la moral de la reciprocidad entra en contradicción con las formas de gestión basadas en el registro, la medición y, en definitiva, con mecanismos que remiten a la contabilidad bancaria mercantilista. Desde la perspectiva teórica, advertimos la contradicción entre por una parte la práctica de la donación, la generosidad, entendidas por los actores sociales como una relación humana presidida por la moral de la reciprocidad que 
rechaza el criterio de la contabilidad bancaria ; y, por otra, la necesidad de la gestión de la organización, presionada por las intituciones públicas, de ordenar la reciprocidad en el registro.

Por último, compartimos la idea de que el concepto de reciprocidad debe ser revisado ya que presenta dificultades de definición si atendemos a la formulación tradicional maussiana , es decir si se piensa la reciprocidad como un principio y no como una relación social; pero a su vez estamos de acuerdo en señalar que el valor o no de este concepto para analizar algunas de las actuales estrategias económicas y políticas exige uma mayor profundidad tanto teórica como empírica.

\section{Lecturas}

BECK, U. (2000): Un nuevo mundo feliz, Barcelona: Paidós.

GerShUNY, J. (1895): «Economic Development and Change in the Mode of Provision of Service», en N. REDCLIFFE \& E. MingIONE (eds.).

HART, D. (1973): "Informal Income Opportunities and Urban Employment in Ghana", Journal of African Studies, 11 (1):61-89.

Mauss, M. (1992): Sociología y Antropología, Madrid: Tecnos.

OfFE, CL., \& R. HEINZE (1989): Beyond Employment Time, Work and the Informal Ecomomy, Phyladelphia: Temple U.P.

POLANYI, K. (1989): La gran transformación, Madrid: La Piqueta.

POLANYI, K. (1994): El sustento del hombre, Barcelona: Mondadori.

ReDCliffe, N., \& E. Mingiones (eds.): Beyond Employment, B. Blackwell.

SAHLINS, M. (1977): La economía de la Edad de Piedra, Madrid: Akal. 